\title{
«ДЛЯ МУЗЕЕВ ЕСТЬ ТАБУ»: ЗАПРЕТИТЕЛЬНЫЕ ПРАКТИКИ В КУЛЬТУРЕ РОССИЙСКИХ МУЗЕЕВ
}

В статье исследуется институт музейных табу. Актуальность исследования обусловлена несколькими факторами, в первую очередь, развитием в последние три десятилетия взаимоотношений «музей-посетитель» и ростом в них роли последнего. Помимо этого, тема важна потому, что именно запреты во многом формируют профессиональную этику, а, следовательно, и сам статус профессии. Целью данной работы было стремление показать неоднозначность современных музейных табу с точки зрения их рациональности и степень влияния последних на функционирование самого музейного института. Основным источником исследования стал опрос музейных сотрудников и анализ систем запретов в музеях Российской Федерации. Главный вывод авторов следующий: современная система музейных табу была сформирована не только отношением к музею как к сакральному пространству, но и культурой советских запретительных практик. Часть профессионального сообщества осознает проблемы с количеством и качеством запретов, однако в иелом обсуждение данной темы само по себе табуировано. Это влечет за собой целый ряд проблем, ключевая из которых - отсутствие единой системы стандартов при работе с посетителем, что становится источником потенциальных конфликтов. Также исследование показало, что в профессиональной музейной среде пока отсутствует консенсус не только по внешним запретам, но и по базовым вопросам внутренней корпоративной культурь.

Ключевые слова: музей, музейная антропология, табу, запреть, корпоративная культура, антропология организаций

«Конечно, есть музеи и церкви, жирные, как домашние коты, они с легкостью задирают иены и вывешивают всевозможные запреть:: их мало кто минует»

Дмитрий Бавальский. «Музей воды»»

В 2016 г. свет увидела книга директора Государственного Эрмитажа М.Б. Пиотровского «Для музеев нет табу. 50 статей за 10 лет» (Пиотровский 2016). Очевидно, что название монографии носит несколько провокационный характер и связано прежде всего с творческими проектами Эрмитажа, которые периодически подвергались критике «общественности» за излишнюю авангардность.

Гринько Иван Александрович - к.и.н., MA in cultural management, начальник управления музейно-туристского развития, ГАУК «МОСГОРТУР», (121099 Москва, 2 Смоленский пер., 1), докторант ИЭА РАН. Эл. почта: iagrinko@yandex.ru

Шевцова Анна Александровна - д.и.н., профессор кафедры культурологии, Московский педагогический государственный университет (119991 Москва, Малая Пироговская, 1).Эл. почта: ash@inbox.ru 
При этом использование термина «табу» не выглядит случайным. Сам М.Б. Пиотровский часто подчеркивал сакральный характер музея, как института. Поэтому не удивительно, что по отношению к музею слово «табу» в отличие от запрета подразумевает специфичность, мнимую или реальную алогичность, ярко выраженную сакрализацию, традиционность и низкую степень формализованности. Несмотря на то, что в современной антропологии данный термин уже не пользуется былой популярностью (Encyclopedia... 2002), на наш взгляд, он еще уместен в исследовательской практике. Примеров того, что тема может быть объектом антропологического анализа, можно привести много. В частности, яростно отстаиваемый музейными сотрудниками, но в большинстве случаев не имеющий особого смысла запрет на фотосъемку в постоянной экспозиции вызывает в памяти распространенное среди традиционных обществ и хорошо знакомое антропологам поверье о том, что фотоаппарат имеет мистические свойства (Wright 2008).

При том, что музейные запреты и ограничения остаются постоянным предметом для шуток и мемов минимум 70 лет (Шевц̧ова, Гринько 2019), попытки конструктивно обсудить эти вопросы в профессиональной среде практически не предпринимаются. Между тем, в любом музее существуют как минимум две группы табу разной степени формализованности: 1) то, что нельзя делать посетителям; 2) внутрикорпоративные запреты и ограничения.

Первая группа значительно больше второй, поскольку сохранение историко-культурного наследия подразумевает ряд серьезных ограничений, традиционное же в профессиональном кругу восприятие музея как храма, а его посещения как квазирелигиозного ритуала (Сорокин 2013, 1995), умножает количество возбранений, табуируя даже обыденное. Duncan Количество только официальных запретов в некоторых музеях достигает двух десятков. Например, в Государственном историческом музее их 15, в Александровском парке, подразделении музея-заповедника «Царское село», - 20, в ГМИИ им. Пушкина и Третьяковской галерее - по 32.

Учитывая отсутствие внятных комментариев, часть из них однозначно воспринимается именно как табу. Ассоциация «музей - запрет» стала настолько прочной, что даже исследователи запретительных надписей в качестве примера берут именно музеи (Покровская, Кудинова 2011). Некоторые антропологи полагают, что уже сам формальный статус музея меняет отношение к пространству и включает ряд самоограничений (Утехин 2012), но далеко не всегда у посетителя есть шанс взять инициативу в свои руки и разобраться, «что в музейной этике продиктовано здравым смыслом, а что - его отсутствием» (Идема 2016: 14).

Помимо формализованных запретов, существуют еще целая система неформализованных, например, на использование телефона, обсуждение экспонатов (Василий Верещагин...) или грудное вскармливание в музейном пространстве (Жильцова 2019; Чемерис 2020). В данном случае мы сталкиваемся с реальным табуированием, поскольку никаких логических обоснований для подобных запретов не приводится.

С учетом того, что функционал музеев продолжает расширяться, а роль посетителей в его деятельности растет (Simon 2010; Dolak, Sobanova 2018) рано или поздно границы табу потребуется пересмотреть, или как минимум перевести их в систему запретов (Покровская, Кудинова 2011). В противном случае, развитая, но при этом не унифицированная система табу станет серьезным тормозом на пути развития музейной сети. Эта дилемма между желанием стать комфортным и демократичным 
пространством, официально заявленным в новом определении музея (Новое определение понятия «музей» 2020), и необходимостью следовать системе запретов и табу может стать одной из ключевых в музейном менеджменте.

Помимо этого, существует и внутрикорпоративные запреты, которые регламентируют функционирование музейного коллектива. Частично они формализованы в Кодексе этики ИКОМ, однако существуют и внутренние ограничения в разных музеях. Все эти запреты и табу прямо или опосредовано влияют на запретительные практики в отношении посетителей.

В данном исследовании была сделана попытка ответить на ряд вопросов, касающихся отношения профессионального сообщества к институту музейных табу. Как музейные сотрудники воспринимают систему внешних и внутренних запретов? Как они трактуют подобные запреты и табу? Как они оценивают их количество?

Данный вопрос ранее не освещался в работах музеологов, хотя, на наш взгляд, это важнейший элемент корпоративной культуры, от которого во многом зависит успешность функционирования музея как социокультурного института. Отдельные исследователи придерживаются точки зрения, что этика и система запретов являются основами музейной профессии (ван Менш 2014). Однако создается ощущение, что сама тема запретов в музее находится под запретом.

В рамках исследования мы опросили 115 сотрудников, представляющих российские музеи разного уровня (федеральные, региональные, муниципальные, частные) через онлайн-форму с полузакрытыми вопросами и множественным выбором. Респондентами стали 98 женщин и 17 мужчин. Кроме того, при работе были использованы открытые интервью с музейными работниками и официальные материалы с сайтов музеев.

Возраст респондентов: моложе 23 лет - 2,6\%, 23-34 года - 32,2\%; 35-44 года 38,3\%; 45-54 - 20,0\%; старше 55 лет - 7,0\%.

При этом 24,4\% опрошенных трудятся в музее менее пяти лет. У $28,7 \%$ респондентов стаж музейной работы 5-9 лет, у 27,8\% - 10-19 лет, у 19,1\% - 20 и более лет, что подразумевает хорошее понимание функционирования музея как системы.

Отношение к системе музейных запретов в целом можно оценить, как индифферентное. Так, на вопрос, мешают или помогают музейным сотрудникам принятые запреты для посетителей, почти половина респондентов (45,2\%) ответила: «Не помогают и не мешают». Остальные мнения распределились следующим образом:

- $4,3 \%$-Только мешают.

- $6,1 \%$ - Скорее мешают.

- $33 \%$ - Скорее помогают.

- $11,3 \%$ - Только помогают.

Индифферентность выразилась и при оценке количества самих запретов. 67,8\% посчитали, что их количество оптимально. Сторонники ужесточения системы запретов остались в меньшинстве - 16,5\%.

Сразу стоит отметить, что ряд музейных запретов не в состоянии логически интерпретировать и считают странными сами сотрудники. Вот примеры подобных табу из российских музеев (стилистика ответов сохранена):

- Смотреть на экспонаты в витринах, стоящих в коридоре, ведущем в выставочный зал.

- Нельзя останавливаться у экспоната. 
- Ходить на экскурсию в сланцах и шевелить пальцами ног.

- Находиться в зале не более 5 минут.

- Не дышать на витрины.

- Не заводить самолет.

- Запрещено обсуждать экспонат экспозиции (родители с детьми).

- Не поворачиваться к картинам спиной!

- Не смотреть в окна.

- Н Не использовать писсуары не по назначению.

Здесь надо подчеркнуть, что речь во многих случаях идет именно о табуировании, а не о запретах, поскольку данные запреты с трудом объясняются логически и скорее направлены на поддержание сакрального порядка в музейном пространстве. В этом признаются и сами сотрудники музея, объясняя, например, запрет на использование сотового телефона: «Этот запрет нигде не прописан - просто это такие этические нормы» (Серебреникова 2013). Хотя нельзя исключать, что введение ряда подобных ограничений связано с печальными прецедентами.

В этом контексте достаточно странно выглядит истовое табуирование сидения на полу или ступенях, особенно если в музейных залах нет стульев или скамей, а в музее, например, организовано учебное занятие, подразумевающее минимум 45-минутное нахождение в зале. Как писал Томислав Шола, «Церковь, которая целиком полагается на веру, послушание и некоторый мазохизм своих прихожан, может позволить себе игнорировать их уставшие ноги и больные спины, но музеи - нет» (Шола 2013: 62).

Парадоксально, что несмотря на очевидную сакрализацию музейного пространства, часть запретов имеет ярко выраженный антирелигиозный характер, например, запрет проводить молебны в Русском музее или «прикладываться к иконам» в Музее русской иконы.

Иногда строгость ограничений компенсируется необязательностью их соблюдения, например, категорический и обозначенный в правилах посещения запрет «проносить живые цветы» обходится, если букет предназначен в подарок художнику или куратору. Аналогичная ситуация существует и с табуированием алкоголя (Гринько 2018).

Среди опрошенных музейных сотрудников $15,7 \%$ считают, что число запретов в музее избыточно. При этом в вопросе о введении новых ограничений 45,2\% респондентов высказалась еще категоричнее: «Никаких дополнительных запретов».

Очевидно, что многие из запретов прямо противоречат новой парадигме музея, как «пространства демократизации, инклюзии и полифонии мнений, созданного для критического осмысления и обсуждения прошлого и будущзего» (ИКОМ, официальный сайт). Так в некоторых музеях запрещается «комментировать пояснения научного сотрудника, вступать с ним в полемику». Интересно, что Белорусский государственный музей истории ВОВ, который еще в 2017 г. попал в прессу из-за такого табу, убрал его из списка запретов, оставив менее определенное «перебивать экскурсовода, а также иньми способами препятствовать проведению экскурсии» (Белорусский государственный музей истории ВОВ, сайт). Нельзя «перебивать экскурсовода», то есть, по сути, задавать вопросы по ходу рассказа, а не в конце экскурсии в ритуальные полторы минуты («Вопросов нет? Так, мальчик, слезь оттуда. Всего доброго, все свободны»), во множестве других музеев, например, в Музее Великой Отечественной войны на Поклонной горе. Возможно, некоторые музеи начали осознавать негативное влияние наличия лишних запретов на свой публичный 
образ, однако, к сожалению, в десятках музеев по-прежнему запрещается «вступать в полемику с музейным сотрудником».

Йохан Идема называет музейных смотрителей «глазами музея» и «пехотой мира искусства». По его словам, «чтобы справиться со всеми фотолюбителями, нарушителями правил проноса газировки и начинающими арт-критиками, смотрители должны обладать бдительностью полицейского и чуткостью воспитательницы в детском саду» (Идема 2016: 19). Интервью с этими многосторонними специалистами, ответственными за соблюдением правил и запретов, показывают, что они всерьез воспринимают табуирование многих вещей: «По пятницам с 17.00 до 19.00 у нас бесплатный вход, и тяжело следить за потоком людей, надо не пропустить никого даже с бутылкой воды, потому что мы не знаем, что в этой воде» (Смородинова 2020).

Очевидно, что здесь, с одной стороны, мы сталкиваемся с классическим табу, поскольку у смотрителя, очевидно, нет логического понимания запрета, с другой стороны, чувствуются и отголоски советских массовых фобий, уже описанных антропологами (Архипова, Кирзюк 2020). Влияние советской охранительной культуры возникает не на пустом месте, а зачастую культивируется внутренними музейными документами. Вот отрывок из «Инструкции для начинающего смотрителя» (Козьмодемьянский музейный комплекс 2020, сайт): «Ваша бдительность удваивается при наличии необычных посетителей. Посетитель, представляющийся как гость хранителя, фотограф, срочно вызванный слесарь, носильщик, которому поручено забрать экспонат для выставки... Проконтролируйте основания их визита. Никому не доверяйте заранее».

Несмотря на возможную обоснованность подобных инструкций, их тональность и формулировки близки к советскому агитационному плакату 1930-1950-х годов из серии «Будь бдителен», и на наш взгляд, не совсем подходят для выстраивания корпоративной культуры в XXI веке.

Традиция следования подобным табу настолько глубока, что необходимость следить за их соблюдением по-прежнему включают даже в учебники для экскурсоводов (Скобельцыьна, Шарухин 2018), функционал которых все же отличается от функционала смотрителей. Эта сакрализация прошлого и ушедшего, в том числе представление об «инструкциях, написанных кровью» и вере в то, что пенсионер на стульчике в углу сможет в одиночку противостоять злоумышленнику, вооруженному пепси-колой, - распространенный музейный грех, который Шола называет «пасеотропией» (Шола 2013: 246).

Любопытен список потенциальных запретов, которые музейщики хотели бы видеть в своих музеях (стилистика ответов сохранена):

- $\quad$ Соблюдение правил поведения детьми (для контроля родителями) $-3,5 \%$.

- Не посещать музей в состоянии алкогольного опьянения $-4,3 \%$.

- Не посещать музей в верхней одежде и с большими сумками $-4,3 \%$.

- Не проносить с собой еду/напитки $-6,1 \%$.

- Не трогать экспонаты $-6,1 \%$.

- Громко разговаривать $-10,4 \%$.

- Другое $-23,5 \%$.

- Никаких дополнительных запретов $-45,2 \%$.

Помимо вполне обоснованных и логичных запретов, которые связаны с сохранностью музейных экспонатов (отказ от больших сумок), здесь, как это ни странно, 
мы видим базовый и имеющийся в правилах посещения практически каждого музея запрет на прикосновения к экспонатам. Показательно, что наибольшей популярностью пользуется потенциальный запрет на громкие разговоры, который фактически никак не формализируется (как именно измеряются децибелы?) и позволяет трактовать его в зависимости от пожеланий работников музея.

Нельзя не отметить, что под «Соблюдением правил поведения детьми» может скрываться и многочисленные табу, связанные с появлением в музеях маленьких детей: кормление грудью, использование колясок и т. д. В данном случае речь действительно идет об откровенном табуировании, а не о логически обусловленном запрете, поскольку музей может разрешать использование колясок людьми с ОВ3, и в то же время вводить запрет на детские. При этом, вводя подобные запреты, музеи формально нарушают законодательство, которое относит родителей с колясками (а также детей, беременных и кормящих женщин, лиц с временными нарушениями здоровья, лиц с избыточным весом; лиц старших возрастов) к маломобильным группам граждан.

Многие музейные сотрудники согласны с тем, что ряд запретов следует отменить, так как они начинают негативно сказываться на посетительском опыте, а, следовательно, и на посещаемости музея. Среди вариантов ответа на вопрос, какой из запретов для посетителей музеев вам кажется лишним, были отмечены:

- Употребление бутилированной воды - 3,5\%

- З Запрет на проход с небольшими животными -3,5\%

- Обсуждение экспозиции - 3,5\%

- Фотосъемка (в том числе бесплатная) - $12,2 \%$

- Другое - 23,5\%

- Таких запретов нет $-53,9 \%$

Два пункта из этого перечня напрямую противоречат списку желаемых запретов, что подчеркивает отсутствие согласия о границах и содержании запретов внутри самого профессионального сообщества. Это влечет за собой отсутствие единых стандартов работы с посетителем, что в итоге негативно сказывается на образе отрасли в целом. Интерес вызывает пункт с платной фотосъемкой, которая уже была признана незаконной прокуратурой и судами субъектов Российской Федерации (Ларцева 2018).

Что касается системы внутренних табу, снова половина респондентов (48,7\%) ответила «не помогают и не мешают», что подчеркнуло слабую рефлексию на тему запретов. Остальные мнения распределились следующим образом:

- $10,4 \%$-Только мешают.

- $10,4 \%$ - Скорее мешают.

- $22,6 \%$ - Скорее помогают.

- $7,8 \%$ - Только помогают.

Из действующих запретов в музеях респонденты отметили следующие:

- Нарушать трудовую дисциплину (опоздания, несоблюдение этики, дресс-кода и т. д.);

- Принимать пищу на рабочем месте;

- Дискредитировать работу учреждения, обсуждать рабочие моменты в соцсетях);

- Обсуждать заработную плату;

- Принимать подарки; 
- Проводить экскурсии без согласования;

- Отвечать грубостью на грубость посетителей;

- Фотографироваться в фондах.

Как видно из этого списка, большая часть запретов носит общекорпоративный характер. Среди них стоит отметить пункт об обсуждении рабочих моментов в социальных сетях, который вызвал бурные дискуссии на фестивале Интермузей-2019. Речь шла даже о создании отдельного кодекса для сотрудников, посвященного поведению в виртуальном пространстве (Русский музей... 2019). Однако при этом сама лексика обсуждения, например, утверждение, что сотрудники «странно комментируют многие вещиџ», больше говорили о желании ввести табу, чем о структурной работе по внедрению корпоративной культуры. Любопытен последний пункт с фотографированием в фондах: в зависимости от контекста и статуса музейного сотрудника появление в социальных сетях фотографии с музейными предметами может стать как объектом восхищения, так и жесткой неконструктивной критики, что еще раз подчеркивает проблемы в согласовании профессиональных норм.

При этом, среди узкопрофессиональных ограничений, в отличие от списка внешних запретов, трудно найти откровенные табу - так или иначе они вытекают из интересов музея как института, идет ли речь об источниках внебюджетного финансирования или о безопасности фондов. Возможно, поэтому абсолютное большинство респондентов не смогло найти ответ на вопрос, какой запрет для работников в вашем музее вам кажется лишним.

- Несоблюдение дресс-кода (запрет на джинсы, футболки без лого музея и т. д.) $-7,8 \%$.

- Запрет на научно-исследовательскую деятельность - 3,5\%.

- $\quad$ Запрос у охраны для перемещения по музею $-1,7 \%$.

- Таких запретов нет $-80 \%$.

- Другое - 3,5\%.

По сути, профессиональное сообщество считает сложившуюся систему запретов достаточной и адекватной. Очевидно, что указанные случаи с запретом на научно-исследовательскую деятельность или передвижения по музею являются исключением из правил, а единственным значимым запретом является соблюдение дресс-кода. Последнее можно расценивать как довольно прохладное отношение к корпоративной культуре.

Ответы на вопрос «Какой запрет Вы бы хотели ввести для работников?» больше касаются внутренней жизни рабочего коллектива и не несут музейной специфики. Опять же показателен взгляд части респондентов на необходимость соблюдения дресс-кода, и его противоречие предыдущей подборке.

- Несоблюдение дресс-кода - 7,8\%.

- Перекладывать работу на других $-4,3 \%$.

- Частые перекуры $-1,7 \%$.

- Есть на рабочем месте $-3,5 \%$.

- Обсуждать личные дела при посетителях, громко разговаривать, сплетничать $-9,6 \%$.

- Таких запретов нет $-48,7 \%$.

- Другое $-24,3 \%$. 
Здесь показательно количество респондентов, считающих, что необходимость в лишних запретах для коллег отсутствует. В то же время, из внимания профессионального сообщества выпали некоторые табу, которые обеспечивают устойчивое развитие сообщества, предотвращая очевидный конфликт интересов, - например, членство (или даже председательство) в жюри конкурса, где участвует ваш музей.

Следует признать, что табуирование и запретительная тональность в современном музее прямо противоречит его магистральным линиям развития. Для модернизации системы запретов и приведение ее в соответствие с запросами сегодняшнего дня необходимы как минимум четыре важных инструмента. Первый - четкое и вежливое объяснение запрета, которое мотивирует посетителя: «Так, например, типичному для всех русских музеев объявлению «Руками не трогать» соответствует куда более пространный итальянский вариант «Per favore non toccate le sculture. Le superficie possono essere denneggiate anche dalle mani pulite» (Пожалуйста, не трогайте скульптуры. Поверхность может быть повреждена даже чистыми руками)» (Покровская, Кудинова 2011: 44).

Во-вторых, представляется полезным использование юмора, который во многих случаях сам по себе табуирован в музеях. Но юмор может сгладить потенциально конфликтную ситуацию, сокращает дистанцию с посетителем и снимает негатив с запрета (Гринько 2017). Более того, юмористически оформленный запрет может быть распространен в социальных сетях и медиа, что позволит заранее подготовить будущих посетителей к правилам музея. Здесь мы подходим к третьему моменту - непрямой стратегии работы с посетителями, например, через пособия о нормативном поведении для детей (Шалаева 2009). Однако этот вариант невозможен без хотя бы приблизительной унификации и стандартизации запретов, что является четвертым условием.

Многие кейсы, упомянутые респондентами, с учетом специфики российского законодательства, могут и должны стать предметом отдельных судебных разбирательств.

Пока же можно сделать следующие предварительные выводы по поводу института музейных табу в российских музеях.

- По факту, посетитель музея зачастую сталкивается с набором табу, а не единой системой аргументированных и прозрачных запретов.

- Данная система продуцируется восприятием музея как сакрального пространства и культурой советских запретительных практик, при этом музеи отказываются признать простую мысль, что «граждане не должны быть благодарны кому-либо за то, что по праву принадлежит им с точки зрения гуманистической этики» (Шола 2013: 82).

- Часть профессионального сообщества осознает проблемы с количеством и качеством запретов, однако в целом обсуждение запретов само по себе табуировано.

- Отсутствует единая система стандартов при работе с посетителем. Это очень важный момент, поскольку он становится источником потенциальных конфликтов с посетителями, которые из опыта посещения нескольких музеев могут сформировать определенную систему поведения, которая может быть расценена как нарушение правил.

- В профессиональной среде пока отсутствует консенсус по базовым вопросам внутренней корпоративной культуры.

В целом, современную ситуацию с запретами можно трактовать как проявление системного кризиса институтов российской музейной сети. 


\section{Источники и материалы}

Белорусский государственный - Сайт Белорусского государственного музея истории ВОВ. http://www.warmuseum.by/index.php/o-muzee/pravila-povedeniya-v-muzee (дата обращения: 22.06.2020).

Василий Верещагин - Василий Верещагин и война взглядов: скандал вокруг экскурсий в Третьяковке // Артхив. https://artchive.ru/news/3500 Vasilij_Vereschagin_i_vojna_ vzgljadov_skandal_vokrug_ekskursij_v_Tret'jakovke (дата обращения: 07.04.2020).

Жильцова - Жильцова Д. «Достали эти овуляхи»: почему женщин «гоняют» за кормление грудью в музеях Москвы. 12.11.2019. https://riamo.ru/article/392281/dostali-eti-ovulyahi-pochemuzhenschin-gonyayut-za-kormlenie-grudyu-v-muzeyah-moskvy.xl (дата обращения: 07.04.2020).

ИКОМ - Официальный сайт ИКОМ. https://icom.museum/en/standards-guidelines/museumdefinition/ (дата обращения: 22.06.2020).

Козьмодемьянский музейный - Сайт Козьмодемьянского музейного комплекса. http://www. kmkmuzey.ru/fondymuzeya/instsmotr (дата обращения: 04.04.2020).

Новое определение - Новое определение понятия «музей» // ИКОМ России. http://icomrussia.com/data/events/novoe-opredelenie-ponyatiya-muzey/ (дата обращения: 07.04.2020)

Русский музей - Русский музей планирует ввести кодекс этики для сотрудников. 30.05.2019// TACC. https://tass.ru/kultura/6495612?fbclid=IwAR3MhnXSSCsQBvJrizwC9YkEg2XFTLFa 6NN8753u5QobdoTZhHXEYolm-hs (дата обращения: 04.04.2020).

Серебренникова - Серебренникова К. Только без рук // Новые Известия. 04.10.2013. https:// newizv.ru/news/society/04-10-2013/190134-tolko-bez-ruk (дата обращения: 07.04.2020)

Смородинова - Смородинова Е. Руками не трогать // Телеканал «Поехали». https://www. poehali.tv/adventures/9202 (дата обращения: 04.04.2020).

Чемерис - Чемерис А. «С этим надо дома сидеть»: Двум мамочкам запретили кормить малышей грудью в Эрмитаже // Комсомольская правда. 25.02.2020. https:/www.spb.kp.ru/ daily/27096/4169404/ (дата обращения 07.04.2020).

\section{Научная литература}

Архипова А., Кирзюк А. Опасные советские вещи: Городские легенды и страхи в СССР. М.: Новое литературное обозрение, 2020. $536 \mathrm{c}$.

Гринько И.А. Юмор в музейном пространстве // Обсерватория культуры. 2017. Т. 14, № 3. С. 315-321. Гринько И.А. В поисках зинфанделя // Музей. 2018. № 11. С. 33-36.

Идема Й. Как ходить в музей. М.: Ад Маргинем Пресс, 2016. 128 с.

Лариева Л. Правомерность взимания платы за фотосъемку в музее // Учреждения культуры и искусства: бухгалтерский учет и налогообложение. 2018. № 4. С. 13-15.

Менш П. ван. Этика и музеология // Вопросы музеологии. 2014. № 1 (9). С. 128-138.

Гринько И. А., Гнедовский М. Б. (ред.) Музейные стандарты: международный опыт: колл. монография [Электронный ресурс]. М.: Перспектива, 2019. 97 с.

Пиотровский М.Б. Для музеев нет табу. 50 статей за 10 лет. СПб.: Арка, 2016. 304 с.

Покровская E.A., Кудинова E.B. Инструкционно-запретительные надписи как инструмент идеологического воздействия (на материале русского и итальянского языков) // Политическая лингвистика. 2011. № 2. С. 43-48.

Скобельцына А.С., Шарухин А.П. Технология и организация информационно-экскурсионной деятельности. 2-е изд. М.: Юрайт, 2018. 262 с.

Сорокин B.H. Креативные индустрии и музеи: учебное пособие / Мин-во образования и науки РФ, Новосиб. гос. пед. ун-т. Новосибирск: Изд-во НГПУ, 2013. 57 с.

Утехин И.В. Место действия. Публичность и ритуал в пространстве постсоветского города. M.: Strelka Press, 2012. 37 c.

Шалаева Г.П. Правила поведения для воспитанных детей. М.: АСТ, 2009. 160 с. 
Шевцова А.А., Гринько И.А. Музеи и советская сатира // Человек и культура. 2019. № 2. С. 80 96. https://nbpublish.com/library_read_article.php?id=28444 (дата обращения: 07.04.2020) DOI: $10.25136 / 2409-8744.2019 .2 .28444$

Шола Т.С. Вечность здесь больше не живет. Толковый словарь музейных грехов. Тула: Музей-усадьба Л.Н. Толстого «Ясная поляна», 2013. 358 с.

Dolak J., Šobaňova P. Museum presentation. Palacki University Olomouc, 2018. 379 p.

Duncan C. Civilizing Rituals: Inside Public Art Museums (Re Visions: Critical Studies in the History and Theory of Art). Routledge, 1995. $192 \mathrm{p}$.

Simon N. Participatory museum. Santa Cruz: Museum 20, 2010. 390 p.

Barnard A. (ed.) Taboo // Encyclopedia of social and cultural anthropology / ed. by Alan Barnard and Jonathan Spencer. London: Routledge, 2002. 1016 p.

Wright C. «A devil's engine»: Photography and spirits in the Western Solomon Islands // Visual Anthropology: Published in cooperation with the Commission on Visual Anthropology. 2008. No. 21. P. 364-380.

Grinko, Ivan A., Shevtsova, Anna A.*

\section{"There are taboos for museums": prohibitive practices in the culture of Russian museums}

DOI: $10.33876 / 2311-0546 / 2020-52-4 / 125-135$

This article analyzes the institute of museum taboos. The relevance of this study is due to several factors, primarily the development of relationships between the museum and the visitor in the last three decades. The prohibitions also influence the shaping of professional ethics, and, consequently, the status of the profession. The main aim of this work was to show the ambiguity of the contemporary taboos in Russian museums and their impact on the functioning of the museum itself.

The research was mainly based on a survey of museum employees and analysis of the systems of prohibitions in museums of the Russian Federation. The main conclusion of the research is as follows: the contemporary system of museum taboos was formed not only by attitude to the museum as a sacred space, but also by the culture of Soviet prohibitive practices. Part of the professional community is aware of the problems with the quantity and quality of prohibitions, however, in general, the discussion of prohibitions is taboo itself. This entails a number of problems, the key one being the absence of a unified system of standards in working with a visitor, which is a cause of potential conflicts. The study showed that in the professional museum community there is still no consensus not only on external prohibitions, but also on basic issues of internal corporate culture.

Key words: museum, museum anthropology, taboos, bans, corporate culture, anthropology of organizations

* Grinko, Ivan - PhD in history, MA in cultural management, Head of the Department for Museum and Tourism Development, SAIC “MOSGORTUR”(Moscow, Russia). E-mail: iagrinko@yandex.ru Shevtsova, Anna - Doctor of Historical Sciences, Professor at the Department of Cultural Studies, Moscow State Pedagogical University (Moscow, Russia). E-mail: ash@inbox.ru

\section{References}

Arhipova, A. and A. Kirzyuk. 2020. Opasnye sovetskie veshchi: Gorodskie legendy i strahi v SSSR. [Dangerous Soviet things: Urban legends and fears in the USSR]. Moscow: Novoe literaturnoe obozrenie. 
Dolak, J. and P. Šobaňova. 2018. Museum presentation. Palacki University Olomouc. 379 p.

Duncan, C. 1995. Civilizing Rituals: Inside Public Art Museums (Re Visions: Critical Studies in the History and Theory of Art). Routledge.

Grin'ko, I.A. 2017. Yumor v muzejnom prostranstve. [Humor in the museum space]. Observatoriya kul'tury. Vol. 14 (3) :315-321.

Grin'ko, I.A. 2018. V poiskah zinfandelya. [In Search of the Zinfandel]. Muzej. 11:33-36.

Grin'ko, I.A. and M.B. Gnedovskyi Muzejnye standarty: mezhdunarodnyj opyt: kollektivnaya monografiya. [Museum standards: international experience: a collective monograph], edited by I.A. Grin'ko; M.B. Gnedovskyi. Moscow: Perspektiva.

Idema, J. 2016. Kak hodit'v muzej. [How to visit an art museum]. Moscow: Ad Marginem Press.

Larceva, L. 2018. Pravomernost' vzimaniya platy za fotos"emku v muzee. [Legality of charging fees for photographing in a museum]. Uchrezhdeniya kul'tury $i$ iskusstva: buhgalterskij uchet $i$ nalogooblozhenie 4:13-15.

Mensh, P. van. 2014. Etika i muzeologiya [Ethics and museology]. Voprosy muzeologii 1 (9): 128-138.

Piotrovskij, M.B. 2016. Dlya muzeev net tabu. 50 statej za 10 let. [There are no taboos for museums. 50 articles in 10 years]. St. Petersburg: Arka.

Pokrovskaya, E.A. and E.V. Kudinova. 2011. Instrukcionno-zapretitel'nye nadpisi kak instrument ideologicheskogo vozdejstviya (na materiale russkogo i ital'yanskogo yazykov). [Instructions and prohibitions as an instrument of ideological influence (based on the material of the Russian and Italian languages)]. Politicheskaya lingvistika 2: 43-48.

Shalaeva, G.P. 2009. Pravila povedeniya dlya vospitannyh detej. [Rules of conduct for raised children]. Moscow: AST.

Shevtsova, A.A. and I.A. Grinko. 2019. Muzei i sovetskaya satira [Museums and Soviet satire]. Chelovek $i$ kul'tura 2: 80-96. https://nbpublish.com/library_read_article.php?id=28444 (accessed 04.04.2020). DOI: 10.25136/2409-8744.2019.2.28444

Shola, T.S. 2013. Vechnost' zdes' bol'she ne zhivet. Tolkovyj slovar' muzejnyh grekhov. [Eternity doesn't live here anymore. Dictionary of the Museum Sins]. Tula: Muzej-usad'ba L.N. Tolstogo «YAsnaya polyana».

Simon, N. 2010. Participatory museum. Santa Cruz, Museum 20.

Skobel'cyna, A.S. and A.P. Sharuhin. 2018. Tekhnologiya i organizaciya informacionnoekskursionnoj deyatel'nosti. [Technology and organization of information and excursion activities]. $2^{\text {nd }}$ ed. Moscow: Yurajt.

Sorokin, V.N. 2013. Kreativnye industrii i muzei: uchebnoe posobie. [Creative industries and museums: a manual] / Min-vo obrazovaniya i nauki RF, Novosib. gos. ped. un-t. Novosibirsk: Izdatel'stvo NGPU.

Taboo In Encyclopedia of social and cultural anthropology. 2002. Ed. by Alan Barnard and Jonathan Spencer. London: Routledge.

Utekhin, I.V. 2012. Mesto dejstviya. Publichnost'i ritual v prostranstve postsovetskogo goroda. [Scene. Publicity and ritual in the space of the post-Soviet city]. Moscow: Strelka Press.

Wright, C. 2008. «A devil's engine»: Photography and spirits in the Western Solomon Islands. Visual Anthropology: Published in cooperation with the Commission on Visual Anthropology 21: 364-380. 